\title{
HUBUNGAN TINGKAT PENGETAHUAN TENTANG KEPUTIHAN DENGAN PERILAKU PENCEGAHAN KEPUTIHAN PADA REMAJA PUTRI
}

\author{
${ }^{1}$ Menthari H. Mokodongan \\ ${ }^{2}$ John Wantania \\ ${ }^{2}$ Freddy Wagey
}

\author{
${ }^{1}$ Kandidat Skripsi Fakultas Kedokteran Universitas Sam Ratulangi Manado \\ ${ }^{2}$ Bagian Obstetri dan Ginekologi Fakultas Kedokteran Universitas Sam Raulangi \\ Email: mentharim@yahoo.com
}

\begin{abstract}
Leucorrhoea in teenagers can be caused by bad behavior of leucorrhoea precaution. Knowledge is a factor to build behavior in teenager. Method: observational analytic research with cross sectional design with using 200 samples from 4 Senoir high school at Manado and Kotamobagu city purposely. Data is collected by using questionnaire and be analysed by using chi-square. Result: more teenager at Manado and Kotamobagu city have good knowledge of leucorrhoea. More teenager with good knowledge of leucorrhoea have good behavior in leucorrhoea precaution $(53,7 \%)$, while more teenager with poor knowledge of leucorrhoea have poor behavior of leucorrhoea precaution $(66,1 \%)$. There is a relationship between knowledge level of leucorrhoea with behavior of leucorrhoea precaution $(p=0,023)$. Teenager with good knowledge of leucorrhoea is 1,5 times to have good behavior of leucorrhoea precaution ( $P R=1,5 ; 95 \% \mathrm{CI}=1,1-2,2)$. Conclusion: Knowledge of leucorrhoea is related significantly to behavior of leucorrhoea precaution in teenager.
\end{abstract}

Keywords: leucorrhoea, knowledge, behavior.

\begin{abstract}
Abstrak: Keputihan pada remaja dapat disebabkan karena perilaku pencegahan keputihan yang kurang baik. Pengetahuan adalah salah satu faktor terbentuknya perilaku pada remaja. Metode: penelitian analitik observasional dengan rancangan potong lintang menggunakan 200 sampel dari 4 SMA di Manado dan Kotamobagu yang diambil secara tidak acak. Data dikumpulkan dengan menggunakan kuesioner dan dianalisa dengan chi-square. Hasil: remaja di kota Manado dan Kotamobagu lebih banyak memiliki pengetahuan yang baik tentang keputihan. Remaja dengan pengetahuan yang baik tentang keputihan lebih banyak memiliki perilaku yang baik dalam pencegahan keputihan (53,7\%), sementara itu remaja dengan pengetahuan yang buruk tentang keputihan lebih banyak memiliki perilaku yang buruk dalam pencegahan keputihan (66,1\%). Ada hubungan antara tingkat pengetahuan tentang keputihan dengan perilaku pencegahan keputihan pada remaja $(\mathrm{p}=0,023)$. Remaja dengan tingkat pengetahuan yang baik tentang keputihan memiliki kecenderungan 1,5 kali memiliki perilaku pencegahan yang baik ( $\mathrm{PR}=1,5 ; 95 \% \mathrm{CI}=1,1-2,2)$. Simpulan: pengetahuan tentang keputihan berhubungan secara bermakna dengan perilaku pencegahan keputihan pada remaja.
\end{abstract}

Kata kunci: keputihan, pengetahuan, perilaku

Fluor albus/leukorea/cairan putih adalah satu bentuk cairan vaginal dan/atau serviks pada wanita. Fluor albus dapat fisiologis maupun patologis. Fluor albus dikatakan cairan vaginal atau serviks patologis, jika disertai dengan perubahan bau dan warna serta jumlah yang tidak abnormal. Keluhan dapat diserta dengan gatal, gedema genital, disuria, dan nyeri abdominal bawah atau nyeri punggung bawah (LBP). Dalam kondisi normal, terlihat cairan vaginal yang 
jernih, putih berkabut atau kekuningan ketika kering pada pakaian. ${ }^{1}$

Pada remaja, penyebab keputihan adalah perilaku pencegahan keputihan yang kurang baik, yaitu higien yang buruk setelah buang air kecil dan buang air besar, menyebabkan patogen mengkontaminasi vulva. Cuci tangan yang tidak adekuat dapat mengiritasi atau kontaminasi bakteri pada vulva. Pakaian ketat, celana dalam yang tidak menyerap juga dapat menyebabkan iritasi. ${ }^{2,3}$

Pengetahuan adalah salah satu faktor predisposing terbentuknya perilaku pada remaja, yaitu faktor yang memotivasi. Faktor ini berasal dari dalam diri seorang remaja yang menjadi alasan atau motivasi untuk melakukan suatu perilaku. ${ }^{4}$ Pentingnya remaja mengetahui tentang keputihan adalah agar wanita khususnya remaja mengetahui tentang keputihan, tanda dan gejala keputihan, penyebab, dan dapat membedakan antara keputihan fisiologis dan patologis sehingga wanita dapat mencegah, menangani dan segera melakukan pemeriksaan apabila terdapat tanda dan gejala keputihan yang tidak normal.

\section{METODE PENELITIAN}

Penelitian ini merupakan jenis penelitian analitik observasional dengan rancangan potong lintang (cross-sectional). Penelitian dilaksanakan di SMA Negeri 1 Manado, SMA Negeri 3 Kotamobagu, SMA Negeri 1 Kotamobagu dan SMA Negeri 4 Kotamobagu, dengan jumlah sampel 200 orang yang diambil secara tidak acak.

Data penelitian berupa tingkat pengetahuan dan perilaku. Tingkat pengetahuan dikategorikan menjadi dua, yaitu tingkat pengetahuan bail bila skor total benar $\geq 75 \%$ dan buruk bila skor total benar < 75\%. Perilaku dikategorikan menjadi dua, yaitu perilaku baik jika skor $\geq$ 10 dan perilaku buruk jika skor $<10$. Kemudian data dianalisa dengan menggunakan uji statistik chi-square.

\section{HASIL PENELITIAN}

Pada penelitian ini digunakan sampel penelitian sebanyak 200 orang yang diambil secara tidak acak dari 4 SMA, yaitu 50 orang dari SMA Negeri 1 Manado, 50 orang SMA Negeri 3 Kotamobagu, 80 orang dari SMA Negeri 1 Kotamobagu dan 20 orang SMA Negeri 4 Kotamobagu.

Tabel 1.Gambaran Sampel

\begin{tabular}{|c|c|c|c|}
\hline \multicolumn{2}{|c|}{ Kategori } & $\mathbf{N}$ & $\%$ \\
\hline \multirow{7}{*}{ Umur } & 13 & 1 & 0,5 \\
\hline & 14 & 21 & 10,5 \\
\hline & 15 & 33 & 16,5 \\
\hline & 16 & 52 & 26 \\
\hline & 17 & 84 & 42 \\
\hline & 18 & 5 & 2,5 \\
\hline & Tidak diketahui & 4 & 2 \\
\hline \multirow{4}{*}{$\begin{array}{l}\text { Sumber } \\
\text { Informasi }\end{array}$} & $\begin{array}{c}\text { Orang tua / } \\
\text { keluarga }\end{array}$ & 76 & 38 \\
\hline & Media massa & 12 & 6 \\
\hline & $\begin{array}{c}\text { Tenaga } \\
\text { kesehatan }\end{array}$ & 57 & 28,5 \\
\hline & Tidak diketahui & 55 & 27,5 \\
\hline \multirow{5}{*}{$\begin{array}{l}\text { Pendidikan } \\
\text { Terakhir } \\
\text { Org Tua ( } \\
\text { Ibu ) }\end{array}$} & SD & 19 & 9,5 \\
\hline & SMP & 24 & 12 \\
\hline & SMA & 81 & 40,5 \\
\hline & $\begin{array}{c}\text { Perguruan } \\
\text { Tinggi }\end{array}$ & 43 & 21,5 \\
\hline & $\begin{array}{c}\text { Tidak } \\
\text { Diketahui }\end{array}$ & 33 & 16,5 \\
\hline
\end{tabular}

Hasil analisis statistik pada tabel 2 menunjukkan bahwa ada hubungan antara tingkat pengetahuan tentang keputihan dengan perilaku pencegahan keputihan pada remaja $(p=0,023)$. Remaja dengan tingkat pengetahuan tentang keputihan yang baik memiliki kecenderungan 1,5 kali memiliki perilaku pencegahan keputihan yang baik $(P R=1,5 ; 95 \% C I=1,1-2,2)$.

Seperti yang ditunjukkan pada tabel 2 , remaja dengan pengetahuan yang baik tentang keputihan lebih banyak memiliki perilaku yang baik dalam pencegahan keputihan (53,7\%), sementara itu remaja dengan pengetahuan yang buruk tentang keputihan lebih banyak memiliki perilaku yang buruk dalam pencegahan keputihan (66,1\%). 
Tabel 2. Analisis Bivariat Hubungan Tingkat Pengetahuan Tentang Keputihan dengan Perilaku Pencegahan Keputihan

\begin{tabular}{|c|c|c|c|c|c|}
\hline \multirow{2}{*}{$\begin{array}{c}\text { Tingkat } \\
\text { pengetah } \\
\text { uan }\end{array}$} & \multicolumn{2}{|c|}{ Perilaku } & \multirow[b]{2}{*}{$\begin{array}{l}\mathbf{P} \\
\mathbf{R}\end{array}$} & \multirow{2}{*}{$\begin{array}{l}95 \\
\% \\
\text { CI }\end{array}$} & \multirow[b]{2}{*}{$\mathbf{P}$} \\
\hline & Baik & $\begin{array}{c}\text { Buru } \\
\mathbf{k}\end{array}$ & & & \\
\hline Baik & $\begin{array}{c}73 \\
(53,7 \\
\%)\end{array}$ & $\begin{array}{c}63 \\
(46,3 \\
\%)\end{array}$ & 1 , & 1,1 & 0,02 \\
\hline Buruk & $\begin{array}{c}23 \\
(35,9 \\
\%)\end{array}$ & $\begin{array}{c}41 \\
(64,1 \\
\%)\end{array}$ & 5 & 2,2 & 3 \\
\hline
\end{tabular}

\section{BAHASAN}

Perilaku adalah faktor terbesar kedua setelah faktor lingkungan yang mempengaruhi kesehatan individu, kelompok, atau masyarakat. ${ }^{5}$ Pada remaja, penyebab keputihan adalah perilaku pencegahan keputihan yang kurang baik, yaitu higien yang buruk setelah buang air kecil dan buang air besar, menyebabkan patogen mengkontaminasi vulva. Cuci tangan yang tidak adekuat dapat mengiritasi atau kontaminasi bakteri apda vulva. Pakaian ketat, celana dalam yang tidak menyerap juga dapat menyebabkan iritasi. $^{2,3}$

Pada penelitian ini didapatkan bahwa lebih banyak remaja yang memiliki perilaku buruk dalam pencegahan keputihan (52\%), ada $10 \%$ remaja yang sering menggunakan produk pembersih wanita, ada $17,59 \%$ remaja yang tidak mengeringkan genitalia eksterna setelah buang air kecil atau buang air besar dengan menggunakan tisu atau handuk kering, ada $25,76 \%$ remaja yang membersihkan genitalia eksterna dengan arah dari belakang ke depan, ada $17 \%$ remaja yang sering menggunakan celana atau celana dalam ketat dalam aktivitas sehari-hari, ada $8,2 \%$ remaja yang sering memakai celana dalam dengan bahan bukan katun, dan ada $2,5 \%$ remaja yang sering memakai bersama pakaian, pakaian dalam dan handung dengan orang lain. Kelompok ini adalah kelompok remaja yang memiliki risiko tinggi akan mengalami keputihan patologis.

Memakai celana dalam yang terbuat dari katun. Kain katun menyerap lembab dan memberikan sirkulasi udara yang bebas ke area genitalia. Lembab dapat meningkatkan infeksi vagina tertentu. Tidak memakai pakaian yang ketat untuk memberikan sirkulasi udara yang lebih baik. Celana atau jeans yang ketat dapat menyebabkan lembab terperangkap dan menyebabkan iritasi. Hindari penggunaan pengharum atau sabun deodorant, mandi busa dan tisu berwarna. Mereka mengandung bahan kimia yang dapat mengiritasi vagina dan genitalia eksterna. Hindari bilas vagina, karena akan menghilangkan flora normal dri vagina dan jika ada infeksi akan menyebabkan berpindahnya patogen ke alat genitalia yang lebih tinggi. Mengganti pembalut paling sedikit tiga kali sehari. Jika pembalut terlalu banyak menyerap lembab, akan menyebabkan iritasi. Bersihkan genitalia dari depan ke belakang. Bakteri dari daerah rektal dapat menyebabkan infeksi vagina. Hindari penggunaan pakaian maupun handuk orang lain. ${ }^{6}$

Pada penelitian ini didapatkan bahwa ada hubungan yang bermakna antara pengetahuan tentang keputihan dengan perilaku pencegahan keputihan pada remaja. Remaja yang memiliki pengetahuan yang baik tentang keputihan cenderung memiliki perilaku yang baik tentang pencegahan keputihan. Hal ini menunjukkan bahwa perilaku pada remaja dapat dimodifikasi melalui peningkatan pengetahuannya.

Pengetahuan adalah salah satu faktor predisposing terbentuknya perilaku pada remaja, yaitu faktor yang memotivasi. Faktor ini berasal dari dalam diri seorang remaja yang menjadi alasan atau motivasi untuk melakukan suatu perilaku. ${ }^{4}$ Pentingnya remaja mengetahui tentang keputihan adalah agar wanita khususnya remaja mengetahui tentang keputihan, tanda dan gejala keputihan, penyebab, dan dapat membedakan antara keputihan fisiologis dan patologis sehingga wanita dapat mencegah, menangani dan segera melakukan pemeriksaan apabila terdapat tanda dan gejala keputihan yang tidak normal. 
Pada penelitian ini, berdasarkan umur sebagian besar sampel berada dalam kategori remaja pertengahan. Pada masa ini, remaja sedang mengembangkan cara berpikir yang baru untuk membuat keputusan sendiri. Masa remaja adalah masa yang rentan dengan terpaparnya mode atau trend, hal ini sangat mempengaruhi remaja putri dalam berperilaku terutama masalah kebersihan organ genitalia dalam mencegah keputihan. Banyak media yang menyediakan iklan tentang pembersihan organ genitalia akan memicu remaja putri untuk mencoba tanpa memikirkan dampaknya pada organ genitalia, ini disebabkan karena remaja putri kurang mengetahui tentang masalah organ genitalia dan akibat perilaku yang buruk terhadap kesehatan organ genitalia. Umur merupakan faktor penentu dalam tingkat pengetahuan, pemahaman, pengalaman, keyakinan dan motivasi, sehingga umur mempengaruhi perilaku seseorang terhadap objek tertentu. ${ }^{7}$ Dalam perilaku higiene organ reproduksi, maka yang paling mempengaruhi adalah lingkungan keluarga terutama ibu sebagai sumber informasi, karena seorang putri akan belajar dan menganut kebiasaan yang sudah ada sebelumnya dari keluarga terutama dari ibu.

Pada penelitian mengenai gambaran tingkat pengetahuan remaja putri tentang keputihan di SMP Al-Ikhlas Surabaya didapatkan hasil bahwa sebagian besar siswi memiliki pengetahuan yang kurang tentang keputihan. Hal ini berbanding terbalik dengan hasil pada penelitian kali ini, yang dapat disebabkan karena perbedaan umur dan tingkat pendidikan antara SMP dan SMA. Semakin tinggi pendidikan seseorang maka akan semakin mudah untuk menerima informasi, sehingga makin banyak pengetahuan yang dimiliki untuk meningkatkan kesehatan. Perlu adanya upaya peningkatan pengetahuan remaja putri tentang keputihan dan personal higiene khususnya alat genital yaitu dengan memberikan konseling sehingga kejadian keputihan pada remaja putri dapat berkurang.
Remaja wanita harus mengetahui tentang keputihan dan penyebabnya secara dini. Karena pada masa peralihan anakanak ke masa dewasa terdapat perubahanperubahan fisiologis wanita khususnya daerah organ reproduksi dan dapat menjadi masalah pada remaja jika tidak mengetahui permasalahan seputar organ reproduksinya dan hal tersebut merupakan pengalaman yang baru bagi remaja wanita. Banyaknya remaja putri pada penelitian ini yang kadang-kadang melakukan perilaku berisiko keputihan menunjukkan bahwa banyak remaja putri masih belum mengerti dengan benar perilaku-perilaku yang berisiko menimbulkan keputihan. Oleh karena itu, diperlukan pemberian pengertian kepada remaja putri mengenai keputihan dan perilaku pencegahan keputihan.

\section{SIMPULAN DAN SARAN}

Sebagian besar remaja putri di kota Manado dan Kotamobagu memiliki pengetahuan yang baik tentang keputihan. Lebih banyak remaja putri yang memiliki perilaku buruk mengenai pencegahan keputihan. Pengetahuan tentang keputihan berhubungan secara bermakna dengan perilaku pencegahan keputihan pada remaja. Remaja putri yang memiliki pengetahuan yang baik tentang keputihan cenderung 1,5 kali memiliki perilaku yang baik mengenai pencegahan keputihan.

Bagi tenaga kesehatan untuk menggalakkan program penyuluhan kepada remaja putri tentang perilaku menjaga kebersihan organ genitalia dalam mencegah keputihan. Bagi peneliti selanjutnya dapat dijadikan sebagai data untuk peneliti selanjutnya, diharapkan dapat mengambil sampel yang lebih besar dan mewakili populasi yang ada dengan menggunakan pendekatan kualitatif agar dapat lebih mendalam mengetahui perilaku remaja putri tentang menjaga kebersihan organ genitalia dalam mencegah keputihan.

\section{DAFTAR PUSTAKA}

1. Monalisa, Abdul RB, Muhammad DA. Clinical aspects fluor albus of 
female and treatment. IJDV 2012;1(1):19-22.

2. Kokotos F. Vulvovaginitis. Pediatrics in Review 2006;27(3):116.

3. Sikanic ND, Nives $P$, Vlasta $H H$, Amarela LG. Microbiological findings in prepubertal girls with vulvovaginitis.

Acta Dermatovenerol

Croat 2009;17(4):268.

4. Lestary $\mathbf{H}$, Sugiharti. Perilaku berisiko remaja di Indonesia menurut survey kesehatan reproduksi remaja Indonesia (SKRRI) tahun 2007. Jurnal

5. Kesehatan Reproduksi 2011;1(3):137.

6. Maulana HDJ. Promosi kesehatan. Jakarta: EGC; 2009. p.185-6.
7. California State University Northridge. Preventing vaginal infection. Diakses tanggal 9 Oktober 2013. Diunduh dari :

http://www.csun.edu/shc/pdfs/educa tion/preventing_vaginal_infections. pdf

8. Amelia MR, Dewi YI, Karim D. Gambaran perilaku remaja putri menjaga kebersihan organ genitalia dalam mencegah keputihan. Diakses tanggal 8 Januari 2014. Diunduh dari:

http://www.scribd.com/doc/192473 343/MANUSKRIP-MELIZARIZKY 